\title{
TEORI PEDAGOGIK PENDIDIKAN MAHMUD YUNUS
}

\author{
Indah Muliati \\ Universitas Negeri Padang, indahmuliati@fis.unp.ac.id \\ Rini Rahman \\ Universitas Negeri Padang, rinirahman@fis.unp.ac.id
}

\begin{abstract}
This research is a library research, which makes books as the main data source. This research focuses on pedagogical theory developed by Mabmud Yunus. From a variety of searches can be put forward several Pedagogic Theories developed by Mabmud Yunus namely; 1) The purpose of education according to Mabmud Yunus is to prepare students so that when they become adults they will be able and capable of doing the work of the world and the practice of the hereafter so as to create happiness with the world and the hereafter. 2) Mahmud Yunus implements the halaqah and classical teaching system in Madras School, which was developed by Mahmud Yunus is a classical system. 3) Mahmud Yunus in teaching using the lecture method, question and answer (dialogue), assignments, demonstrations, group work and uswatun hasanah (exemplary). 4) In teaching Arabic the Mahmud Yunus uses the direct method. 5) In teaching he uses various approaches namely rational, emotional, and practical approaches. 6) Mabmud Yunus is a figure who pioneered an integrated curriculum in Islamic educational institutions. 7) If you want to improve education and teaching in Indonesia it is important to improve teachers by preparing teachers in teacher schools.
\end{abstract} Keywords: Mahmud Yunus, Pedagogic Theories, Education

\begin{abstract}
Abstrak
Penelitian ini bersifat library reseach, yang menjadikan buku sebagai sumber data utama. Penelitian ini memfokuskan pada teori pedagogik yang dikembangkan oleh Mahmud Yunus. Dari berbagai penelusuran dapat dikemukakan beberapa Teori Pedagogik yang dikembangkan oleb Mahmud Yunus yakni ; 1) Tujuan pendidikan menurut Mahmud Yunus adalah menyiapkan anak-anak didik agar diwaktu dewasa kelak mereka sanggup dan cakap melakukan pekerjaan dunia dan amalan akbirat sebingga tercipta kebahagiaan bersama dunia dan akbirat. 2) Mahmud Yunus melaksanakan sistem pengajaran halaqah dan klasikal di Madras School, yang dikembangkan oleh Mahmud Yunus adalah sistem klasikal. 3) Mahmud Yunus dalam mengajar menggunakan metode ceramah, tanya jawab (dialog), pemberian tugas, demonstrasi, kerja kelompok dan uswatun hasanah (keteladanan). 4) Dalam pengajaran Babasa Arab Mahmud Yunus menggunakan metode langsung (direct metode). 5) Dalam mengajar beliau menggunakan berbagai pendekatan yakni pendekatan rasional, emosional, dan praktis. 6) Mabmud Yunus merupakan tokoh yang mempelopori kurikulum yang bersifat integrated di lembaga pendidikan Islam. 7) Jika hendak memperbaiki pendidikan dan pengajaran di Indonesia penting memperbaiki guru dengan mempersiapkan guru di sekolah guru.
\end{abstract}

Kata Kunci: Mahmud Yunus, Teori Pedagogik, Pendidikan

\section{PENDAHULUAN}

Mahmud Yunus lahir dalam keluarga yang merupakan tokoh Agama terkemuka, ayahnya pengajar surau, kakeknya pendiri dan pengasuh surau di wilayahnya, beliau memiliki paman yang menopang kelanjutan pendidikannya. 
Mahmud Yunus merupakan salah satu tokoh pembaharuan pendidikan Islam di Indonesia. Gagasan dan ide cemerlangnya, membuatnya layak di sebut sebagai tokoh pembaruan di bidang pendidikan di Indonesia.

Tulisan ini merupakan kajian yang bertujuan untuk mengetahui siapa sosok luar biasa seorang Mahmud Yunus sebenarnya, apa saja gerakan pembaharuan yang dilakukannya, teori pedagogik yang dikembangkannya di lihat dalam tujuan pendidikan, sistem pengajaran, metode dan pendekatan mengajar, kurikulum yang dikembangkannya, dan bagaimana pandangan Mahmud Yunus tentang pentingnya dan bagaimana seharusnya seorang guru.

\section{BIOGRAFI DAN GERAKAN PEMBAHARUAN MAHMUD YUNUS}

Mahmud Yunus lahir di Sunggayang, BatuSangkar, Sumatera Barat tanggal 30 Ramadhan 1316 H / 10 Februari 1899 M ayahnya bernama Yunus B. Incek dan ibunya Hafsah binti Imam Sami'un. ${ }^{1}$

Mahmud Yunus berasal dari keluarga yang agamis, ibunya Hafsah binti Imam Samiun, putra Engku Kolok, ulama besar di Sungayang. Sedangkan ayahnya Mahmud Yunus Incek bekas pelajar surau imam masjid di Sungayang. Mahmud Yunus bin Incek dikenal masyarakat seorang yang sangat jujur. ${ }^{2}$

Ketika Mahmud Yunus berumur tiga tahun, orangtuanya bercerai, sementara ibunya menikah lagi. ${ }^{3}$ Tumbuh di tengah keluarga ibunya, Mahmud Yunus sejak kecil sangat menyukai ilmu agama. Beliau mempelajari Alquran dengan kakeknya yang bernama
Engku Gading di Surau Talang, ${ }^{4}$ dalam usia usia tujuh tahun beliau mengkhatamkan Alquran. $^{5}$ Kemudian, beliau menjadi pengajar di surau sebagai pengganti kakeknya. ${ }^{6}$

Beliau mauk ke SR di Sunggayang tahun 1908, setelah empat tahun beliau pindah ke Madras School di Surau Tanjung Pauh. Beliau pindah karena merasa bosan dengan seringnya pelajaran di kelas diulang. Ketika itu Madras School dipimpinan oleh Muhammad Thaib Umar. Beliau mempelajari nahwu, sharaf, bahasa Arab dan matematika di Madras School. ${ }^{7}$

Beliau terlibat dalam gerakan pembaharuan yang digagas oleh Abdullah Ahmad, Abdul Karim Amrullah, dan Mohammad Djamil Djambek. Keterlibatan beliau berawal ketika menggantikan gurunya Muhammad Thaib Umar yang ketika itu sedang sakit, untuk menghadiri pertemuan alim ulama seluruh Minangkabau pada tahun 1919 di Surau Jembatan Besi, Padang Panjang. Pertemuan tersebut menghasilkan kesepakatan mendirikan Persatuan Guru Agama Islam (PGAI), yaitu sebuah organisasi yang merupakan wadah tempat berkumpulnya para ulama Minangkabau yang peduli terhadap pendidikan Islam. Beliau merupakan salah satu anggota pertama PGAI.

Mahmud Yunus bersama aktivis pembaru Islam lainnya membentuk sebuah perkumpulan pelajar Islam di Sungayang pada akhir tahun 1919 yang diberi nama Sumatera Thawalib. Perkumpulan ini menerbitkan majalah Islam yang bernama al-Basyir, dengan beliau sebagai pimpinan redaksinya. Lewat

\footnotetext{
${ }^{4}$ Herry Muhammad, Tokoh-Tokoh Islam yang Berpengaruh Abad 20, (Jakarta: Gema Insani, 2006), 8586.

${ }^{5}$ Rosnani Hashim, Reclaiming..., 169

${ }^{6}$ Mahmud Yunus, Riwayat Hidup..., 14

${ }^{7}$ Saiful Amin Ghofur, Profil Para Mufassir alQuran, (Yogyakarta: Pustaka Insan Madani, 2008), 198
} 
Majalah inilah, beliau menyuarakan pembaruan Islam salah satunya pendidikan ${ }^{8}$.

Mahmud Yunus merupakan yang pertama di Asia belajar di Universitas Darul Ulum Kairo Mesir. ${ }^{9}$ Di universitas ini beliau mempelajari ilmu umum disamping ilmu agama. Pada tahun 1930 beliau kembali ke tanah kelahirannya di Sunggayang setelah menyelesaikan pendidikan di Darul 'Ulum. Di Sunggayang beliau mengajar di Jami'ab alIslamiyah sejak tahun tahun 1931 M, sekaligus memimpin Normal Islam di Padang. ${ }^{10}$ Lembaga pendidikan Normal Islam membawa banyak pengaruh terhadap perkembangan pendidikan Islam "Modern" di Indonesia, di anataranya melalui slah satu alumninya $\mathrm{KH}$. Imam Zarkarsyi, yang merupakan pendiri Pondok Modern Darussalam Gontor Ponorogo Jawa Timur. Sejak tahun 1936 Gontor menggunakan kurikulum dan sistem pendidikan Normal Islam (modern), dalam perkembangan selanjutnya Gontor lebih populer dari pada Normal Islam.

Mahmud Yunus mendirikan Sekolah Tinggi Islam di Padang tanggal 1 November 1940. Namun sayang tanggal 1 Maret 1942 sekolah ini terpaksa ditutup karena Jepang tidak menginginkannya. Mahmud Yunus menolak tawaran menjadi menjadi salah satu dosen PTAIN di Yogyakarta, karena menurut beliau Perguruan tinggi harusnya terletak di pusat, berdasarkan alasan ini beliau berusaha mendirikan PTAIN di Jakarta. Namun sangat disayangkan usaha beliau tidak membuahkan hasil karena ditolak menteri P dan K. Gagal bukan berarti menyerah, Mahmud Yunus beserta kawan-kawan akhirnya mendirikan Akademi Dinas Ilmu Agama (ADIA). Beliaupun diangkat menjadi Dekan ADIA,

\footnotetext{
${ }^{8}$ Abuddin Nata, Tokoh-Tokoh Pembaruan Pendidikan Islam, (Jakarta: Raja Grafindo Persada, 2005), 58

${ }^{9}$ E. Nugroho. et.al, Ensiklopedi Nasional, vol. 17, (Jakarta: PT. Cipta Adi Pustaka, 1991), 435

10 Mahmud Yunus, Sejarah Pendidikan Islam di Indonesia, (Jakarta: Mutiara, 1995), 102
}

beliaupun kemudian mengajukan usulan kepada Menteri Agama agar ADIA menjadi sebuah perguruan tinggi. ${ }^{11}$

Pada masa Pemerintahan Darurat Republik Indonesia (PDRI) usulan Mahmud Yunus untuk mendirikan madrasah tsanawiyyah untuk seluruh Sumatera disetujui oleh Menteri Agama PDRI. Setelah penyerahan kedaulatan dari pemerintah Belanda kepada pemerintah RI, beberapa madrasah Tsanawiyyah yang pada waktu itu bernama Sekolah Menengah Pertama Islam (SMPI), didirikan di Sumatera Barat. Namun Madrasah ini diselenggarakan secara swasta, meskipun beliau telah memperjuangkannya untuk dijadikan sebagai sekolah negeri.

Berdirinya Institut Agama Islam Negeri (IAIN) tidak dapat dipisahkan dari perjuangan Mahmud Yunus. Ketika beliau menjabat sebagai Dekan ADIA. Terpikir oleh beliau untuk menyatukan ADIA dan PTAIN Yogyakarta. Saat beliau menjabat sebagai Kepala Lembaga Pendidikan Agama di bagian Pendidikan Agama, beliau mengajukan usulan kepada Menteri Agama agar ADIA bisa dijadikan sebuah perguruan tinggi sampai pada tingkat sarjana penuh. Menteri Agama pun menyetujui usulan tersebut. Selanjutnya keluarlah Peraturan Presiden Nomor Tahun 1960 tentang pendirian Institut Agama Islam Negeri. Ketika itu IAIN baru memiliki dua fakultas di Jakarta (Fakultas Tarbiyah dan Fakultas Adab), Fakultas Tarbiyah dengan dekan Mahmud Yunus dan Fakultas Adab dengan dekan H. Bustami Abdul Gani. Dua fakultas di Yogyakarta, yaitu Fakultas Syari ${ }^{\text {ee } a h}$ dan Ushuluddin dengan dekan masing-masing Prof Hasbi Ash-Shiddiqy, dan Prof Mukhtar Yahya. $^{12}$

\footnotetext{
${ }^{11}$ Abudin Nata. Tokoh-tokoh Pembaharuan Pendidikan Islam, 60

${ }^{12}$ Malta Rina. Pemikiran dan Karya Prof. Dr. Mabmud Yunus Tentang Pendidikan Islam (1920-1982). http://pasca.unand.ac.id/id. diunduh pada 26 Mei 2016.
} 
Mahmud Yunus terlibat aktif menghadiri forum-forum internasional. Pada bulan April tahun 1962, atas undangan Raja Sa'ud beliau menghadiri sidang Majelis A'la Istisyari Al-Jami"ah Al-Islamiyah di Madinah. Beliau juga berperan aktif sebagai peserta Muktamar Bubutsul Islamiyah di Universitas AlAzhar Mesir sebanyak empat kali muktamar, yakni tahun 1964, 1965, 1966 dan 1967. Tahun 1969, beliau diundang kembali mengikuti Majelis A'la Istisyari Al-Jami'ab Al-Islamiyah di Madinah. ${ }^{13}$

Mahmud Yunus merupakan Rektor pertama pada Perguruan Tinggi Agama Islam Negeri di Sumatera Barat, dan itu merupakan jabatan terakhir beliau selama menjadi pegawai Departemen Agama. Jabatan ini beliau pegang sejak tahun 1967 sampai tahun 1970 ketika beliau memasuki masa pensiun.

Memasuki masa pensiun di awal tahun 1970 beliau mengalami penurunan kesehatan yang membuat beliau diharuskan sering masuk rumah sakit. Pada tahun 1982, beliau mendapat gelar doctor honoris causa di bidang ilmu tarbiyah dari IAIN Jakarta atas karyakaryanya dan jasanya dalam pengembangan pendidikan Islam di Indonesia. Beliau banyak melahirkan karya semasa hidupnya. Beliau wafat pada tahun $1982 .^{14}$

\section{TEORI PEDAGOGIK DIKEMBANGKAN MAHMUD YUNUS}

Tujuan Pendidikan

Tujuan pendidikan menurut Mahmud Yunus adalah mempersiapkan peserta didik supaya kelak diusia matang mereka mmpu dan cakap melaksanakan pekerjaan yang bersifat dunia dan amalan-amalan akhirat, agar tercapai kebahagiaan dunia dan akhirat. ${ }^{15}$

\footnotetext{
13 Ibid.

14 Ibid.

${ }^{15}$ Abudin Nata. Tokoh-tokoh Pembaharuan Pendidikan Islam, 62
}

Tujuan di atas tampak ringkas dan pendek, namun maknanya sangat dalam. Agar peserta didik teguh dalam keimanan dan cakap dalam amal shaleh mereka harus mendapat pendidikan. Supaya peserta didik teguh dalam keimanan dan cakap dalam amal shaleh mereka harus diajarkan: aqidah, akhlak, ibadah dan kandungan Alquran yang berkaitan dengan yang wajib dikerjakan, yang halal dan haram. Supaya peserta didik cakap dalam pekerjaan dunia, mereka harus mendapat pendidikan yang berhubungan usaha, seperti berdagang, bertani,beternak, bertukang, menjadi guru, dan sebagainya sesuai dengan pembawaan masing-masing peserta didik. ${ }^{16}$

Tapi penguasaan ilmu akhirat dan ilmu dunia, menurut Mahmud Yunus tidak boleh lepas dari akhlak. ${ }^{17}$ Karena tujuan Rasulullah SAW, diutus adalah untuk memperbaiki akhlak manusia. ${ }^{18}$ Berdasarkan pemikiran tersebut, beliau menegaskan tugas utama yang jatuh ke pundak para ulama, guru-guru agama dan pemimpin-pemimpin Islam adalah mendidik anak-anak, remaja dan masyarakat agar mereka berakhlak mulia. ${ }^{19}$

\section{Sistem Pengajaran}

Pada mulanya sistem pengajaran yang dilaksanakan di Madras School adalah sistem halaqah. Pada tanggal 4 Oktober 1918 Mahmud Yunus melaksanakan sistem pengajaran klasikal di Madras School, namun untuk pelajar-pelajar dewasa yang datang dari luar Sungayang beliau menggunakan sistem halaqah. Di Madras School beliau mengembangkan sebuah sistem, peserta didik

16 Mahmud Yunus, Pokok-pokok Pendidikan dan Pengajaran, (Jakarta: Hidakarya Agung, 1990), 10

${ }^{17}$ Herry Muhammad, Tokoh-tokoh Islam..., 90

18 Rini Rahman, Dinovia Fannil Kher, and Yati Aisha Rani, "Pendidikan Islam Bagi Remaja (Upaya Penguatan Karakter Dengan Pendekatan Agama," ISLAM TRANSFORMATIF : Journal of Islamic Studies 1, no. 2 (March 6, 2018): 95-104, doi:10.30983/IT.V1I2.473.

${ }^{19}$ Abudin Nata, Tokoh-tokoh Pembaharuan Pendidikan Islam, 63 
belajar pada siang hari dalam kelasnya seperti biasa, pada malam hari sistem pengajarannya berhubungan dengan pengembangan aktivitas peserta didik. Beliau langsung terlibat sebagai fasilitator. Dalam pembelajaran di kelas guru meminta salah satu peserta didik membaca teks Bahasa Arab yang berhubungan dengan materi pada saat itu, peserta didik lain diharuskan memperhatikan. Seandainya penjelasaannya dianggap kurang beliau akan menambahkan penjelasan. Melalui sistem pembelajaran seperti ini peserta didik terlibat aktif dalam pembelajaran. Peserta didik yang mengikuti pembelajaran selama 5-6 tahun akan mampu menjadi pengganti gurunya dalam mengajar. Beliau dekat dengan anak didiknya.

Sistem klasikal dengan pendekatan aktivitas terus dikembangkan di Normal Islam melalui beberapa tahap. Pertama, melalui kontak langsung di ruang kelas, di mana seorang murid dengan berbagai kemampuan yang dimilikinya hadir dalam tatap muka langsung dengan gurunya. Kedua, melalui kontak dan komunikasi secara langsung antara guru dan murid di luar jam belajar. Pertemuan personal seperti itu sangat intensif untuk proses transmisi ilmu pengetahuan. Selama terjadinya kontak dan komunikasi baik di dalam ataupun di luar kelas, dalam berbagai disiplin ilmu kecuali Bahasa Belanda dan Inggris, guru dan peserta didik Normal Islam menggunakan Bahasa Arab. Jadi Bahasa Arab merupakan bahasa pengantar di Normal Islam. Ketiga, melalui diskusi antar peserta didik pada jam belajar yang sudah ditentukan maupun di luar jam belajar. Kontak peserta didik di luar jam belajar biasa disebut dengan murakarah. Kegiatan ini bertujuan untuk mempertajam dan memperluas wawasan keilmuan peserta didik di samping berlatih untuk berargumentasi dengan baik dan benar. Keempat, melalui self study, artinya peserta belajar sendiri agar tugas-tugas yang diberikan oleh guru dapat diselesaikannya. Kegiatan self study biasa dilakukan murid di perpustakaan atau di asrama. ${ }^{20}$

\section{Metode dan Pendekatan dalam Mengajar}

Menurut Mahmud Yunus metode merupakan langkah yang akan digunakan guru dalam mengajar. Langkah tersebut adalah khittah (garis) yang dirancang sebelum mengajar di kelas kemudian diaplikasikan ketika mengajar di kelas. ${ }^{21}$ Karenanya, guru hendaknya mampu menggunakan metode yang efektif dan efesien, sehingga proses pembelajaran tidak menjemukan dan melelahkan. ${ }^{22}$ Seorang guru memberikan appersepsi di awal pembelajaran dengan menghubungkan pembelajaran baru dengan pembelajaran lama, ${ }^{23}$ agar dalam pembelajaran berkesinambungan dan memiliki hubungan yang fungsional. Beliau juga menerapkan langkah-langkah untuk membangkitkan minat dan perhatian peserta didik melalui cara pengaktifan pancaindera, baik itu melalui lisan, tulisan maupun perbuatan. Setelah pembelajaran berakhir materi disimpulkan kemudian diakhiri dengan latihan dan ulangan. $^{24}$

Beliau menggunakan berbagai metode mengajar di Normal Islam, yakni metode ceramah, tanya jawab (dialog), pemberian tugas, demonstrasi, kerja kelompok dan metode keteladanan. ${ }^{25}$ Pada setiap mata pelajaran digunakan metode khusus yang tidak sama dengan mata pelajaran lainnya.

${ }^{20}$ Ramayulis \& Samsul Nizar. Ensiklopedi Tokoh Pendidikan Islam; Mengenal Tokoh Pendidikan di Dunia Islam dan Indonesia, (Ciputat: Quantum Teaching, 2005), 342345

21 Mahmud Yunus. Pokok-pokok Pendidikan dan Pengajaran, 85

22 Ibid.

23 Ramayulis, Sejarah Pendidikan Islam; Perubahan Konsep Filsafat dan Metodologi dari Era Nabi SAW sampai Ulama Nusantara, (Jakarta: Kalam Mulia, 2011), 309

${ }^{24}$ Abudin Nata, Tokoh-tokoh Pembaharuan Pendidikan Islam, 66-67

${ }^{25}$ Ramayulis \& Samsul Nizar, Ensiklopedi Tokoh Pendidikan Islam..., 345 
Oleh karena itu metode (cara-cara) mengajar yang beliau gunakan dapat disimpulkan menjadi dua macam yakni, metode mengajar umum dan metode mengajar modern, metode mengajar umum meliputi :

Metode penyimpulan, yakni, guru menuliskan contoh-contoh di papan tulis selanjutnya dibahas bersama peserta didik, kemudian disimpulkan. Metode ini bertujuan untuk membiasakan murid agar mampu dan terbiasa berfikir sendiri;

Metode Quasiyah, yakni, metode yang dipermulaan pembelajaran disebutkan kaedah dan hukum umum, selanjutnya dijelaskan contoh-contohnya. Metode ini hanya sekedar menerima apa adanya dari guru.

Metode membahas dan mengkiaskan, dalam metode ini guru dan murid bersama menyimpulkan materi dan berpindah kaedah.

Metode memberitakan atau ceramah. Metode ini tidak sesuai untuk peserta didik di sekolah rendah, menengah pertama, dan menengah atas. Metode ini hanya seusai untuk mahasiswa.

Metode bercakap-cakap dan tanya jawab, yakni metode yang menggunakan percakapan dan tanya jawab untuk mendapatkan suatu kebenaran dalam ilmu. Tujuannya agar ilmu pengetahuan dipahami oleh peserta didik dan mereka terbiasa membahas untuk mendapatkan kebenaran ilmiah.

Sedangkan metode mengajar modern yang beliau gunakan adalah: 1) metode menyelidik yaitu membahas mata pelajaran dalam kitab yang ditentukan oleh guru, agar peserta didik mempelajarinya sendiri, dan ditentukan waktunya kapan harus selesai; 2) metode mentakjubkan (menghargai), dalam metode ini peserta didik lebih banyak bersikap pasif, lebih banyak mendengar dari pada berbicara ataupun berbuat, guru menyentuh hati peserta didik dengan penuh kasih sayang, sehingga guru dapat membawa peserta didik kepada tujuan yang diinginkan; 3) metode latihan (Drill), dalam metode ini lebih banyak digunakan latihan dan ulangan.

Dalam pengajaran Bahasa Arab, Mahmud Mahmud Yunus mempergunakan Thariqah al-Mubasyarah atau metode langsung (direct metode). Metode ini beliau gunakan dengan menggunakan pola pikir sebagai berikut : Jika di sekolah-sekolah yang didirikan Belanda untuk masyarakat pribumi dari golongan aristokrat, seperti HIS, MULO, dan AMS, bahasa Belanda digunakan sebagai Bahasa pengantar, maka sangatlah sesuai jika dalam belajar di madrasah Bahasa Arab digunakan sebagai bahasa pengantar dalam mempelajari semua mata pelajaran. ${ }^{26}$ Buku Durus al-Lughah al-'Arabiyah empat jilid yang beliau tulis ketika masih belajar di Mesir digunakan sebagai sumber pembelajaran Bahasa Arab di madrasah dengan menggunakan metode langsung. ${ }^{27}$

Hadirnya metode ini merupakan reaksi terhadap penggunaan grammar-translation method yang mengajarkan bahasa seperti bahasa tanpa makna. Hal ini dimaksudkan bahwa grammartranslation method tidak bisa mengatasi kemampuan komunikasi lisan, dan lebih menekankan pada penggunaan spontan dari bahasa kedua, selain mengembangkan kemampuan berpikir dalam bahasa target. Secara reflektif, metode ini mencoba menjauhkan diri dari model grammar-translation method yang menggunakan bahasa pertama sebagai pengantar pembelajaran, menghafal aturan tata bahasa dan menterjemahkan antara bahasa pertama dengan bahasa target.

Metode langsung atau dikenal dengan Direct Method merupakan metode yang menekankan pada kemampuan menyimak dan berbicara. Pembelajaran bahasa dalam metode ini menekankan perhatian terhadap hubungan antar kata dan frase dengan benda atau dalam

26 Mahmud Yunus, Riwayat Hidup Prof. DR. Mabmud Yunus, 105

${ }^{27}$ Ramayulis \& Samsul Nizar, Ensiklopedi Tokoh Pendidikan Islam..., 345 
bentuk tindakan nyata, bahasa ibu peserta didik tidak digunakan sedikitpun. Kecakapan berkomunikasi secara lisan dikembangkan melalui tahapan yang direncanakan dengan matang. Kegiatan komunikasi ini dilakukan dalam kegiatan tanya jawab di kelas kecil secara insentif antara guru dan siswa. Sedangkan untuk tatabahasa diajarkan kepada peserta didik secara induktif melalui kalimatkalimat yang diucapkan oleh guru kepada peserta didik, pada akhirnya lama-lama peserta didik bisa mengambil kesimpulan secara mandiri bagaimana kalimat yang benar, selain itu untuk materi baru diperkenalkan pertama kali kepada peserta didik secara lisan". ${ }^{28}$

Kelebihan Metode Mubasyarah/Direct Method ; (1) Peserta didik terampil menyimak dan berbicara, (2) Peserta didik mampu melafalkan kalimat dengan baik seperti mendekati penutur asli, (3) Peserta didik mengenal dan hafal banyak kosa kata dan bagaimana pemakaiannya dalam kalimat (4) Peserta didik berani dan spontanitas dalam berkomunikasi karena dilatih berfikir dalam bahasa sasaran sehingga tidak terhambat oleh proses penerjemahan, (5) Peserta didik menguasai tata bahasa secara fungsional tidak secara teoritis. ${ }^{29}$

Mahmud Yunus dalam mengajar juga menggunakan berbagai pendekatan yakni pendekatan rasional, emosional, dan praktis. Pendekatan rasional dalam belajar dengan cara memberikan penekanan pada pendalaman materi dengan tujuan membawa peserta didik mampu berpikir kritis, sehingga peserta didik bisa menggunakan rasionya dengan maksimal. Pendekatan emosional dalam proses pembelajaran memberi penekanan bagaimana seorang guru diharuskan mampu menanamkan

28 A. Syukur Ghazali, Pembelajaran Keterampilan Berbahasa; Dengan Pendekatan Komunikatif-Interaktif. (Bandung: Aditama, 2010), 94.

${ }^{29}$ Acep Hermawan, Metodologi Pembelajaran Bahasa Arab, (Bandung: PT Remaja Rosdakarya, 2001), 104105.

moral kepada peserta didik. Pendekatan praktis dalam kegiatan pembelajaran memberikan penekanan pada pengembangan semaksimal mungkin kecakapan peserta didik, sehingga selain cerdas, peserta didik juga dapat mengaplikasikan ilmu pengetahuan yang didapatnya di tengah masyarakat ${ }^{30}$.

\section{Kurikulum}

Mahmud Yunus yang merupakan pembaharu pendidikan Islam yang perdana mempelopori adanya kurikulum yang bersifat integrated, yakni kurikulum yang memadukan antara ilmu agama dan ilmu umum di lembaga pendidikan Islam. Mahmud Yunuslah tokoh yang pertama kali memasukkan mata pelajaran umum ke dalam kurikulum madrasah, beliau pula yang pertama kali membuat laboratorium fisika dan mendirikan Pendidikan Guru Agama (PGA). Beliau juga orang yang pertama kali berusaha memasukkan pendidikan agama pada kurikulum pendidikan umum yang berada di bawah naungan Departemen Pendidikan Nasional. Beliau merupakan tokoh yang menekankan pentingnya akhlak mulia melalui lembaga pendidikan. Beliau juga merupakan orang pertama yang berhasil mendirikan Perguruan Tinggi Agama Islam. $^{31}$ Beliau berusaha merefleksikan keseimbangan antara ilmu agama dan ilmu umum yang selama ini belum dikenal di madrasah tradisional. ${ }^{32} \mathrm{Hal}$ ini dapat dilihat pada kurikulum Normal Islam sebagai berikut:

Kurikulum Normal Islam Padang:

1. Ilmu-ilmu Agama Islam (Kurikulum ini tidak dirinci, namun dalam prakteknya dirinci menjadi : Tafsir, Hadits, Figh/Ushul Fiqh)

${ }^{30}$ Ramayulis \& Samsul Nizar, Ensiklopedi Tokoh Pendidikan Islam..., 346

${ }^{31}$ Abudin Nata. Tokoh-tokoh Pembaharuan Pendidikan Islam, 56

${ }^{32}$ Ramayulis \& Samsul Nizar, Ensiklopedi Tokoh Pendidikan Islam..., 346 
2. Bahasa Arab; Insyak, Muthala'ah, Mahfurhat, Qawa'id, Adabul Lughah

3. Ilmu-ilmu Umum; Ilmu Ukur, Aljabar, Ilmu Hayat/Geologi, Ilmu Alam/Kimia, Ekonomi, Tarekh Islam, Ilmu Bumi/Ilmu Falak, Sejarah Indonesia/Dunia, Tata Negara, Bahasa Inggris/Bahasa Belanda, Olahraga, Ilmu Kesehatan, Ilmu Pendidikan, Ilmu Jiwa, Khat/Menggambar ${ }^{33}$.

Dari pembagian ilmu di atas dapat dipahami bahwasanya kurikulum Normal Islam lebih memprioritaskan Ilmu Pengetahuan Umum dibandingkan dengan Ilmu Pengetahuan Agama dan Bahasa Arab.

Meskipun ilmu pengetahuan umum lebih besar porsinya dari ilmu pengetahuan agama, bagi Mahmud Yunus prioritas pendidikan sebenarnya terletak pada pembentukan kepribadian dan pendidikan moral. ${ }^{34}$ Oleh karena itu menurut Mahmud Yunus, semua mata pelajaran baik pengetahuan agama maupun pengetahuan umum bermuara pada tujuan pendidikan Islam, yaitu membentuk insan paripurna yang taqwa kepada Allah, cerdas, cakap, trampil, tangkas dan berkepribadian mulia yang diridhai oleh Allah swt. ${ }^{35}$

Selain itu beliau merupakan peletak dasar pembelajaran Bahasa Arab di Indonesia. Beliau menekankan pentingnya pembelajaran Bahasa Arab karena Bahasa Arab merupakan kunci untuk mempelajari ilmu-ilmu keislaman.

33 Zuhairini dkk, Sejarab Pendidikan Islam, (Jakarta: PT Bumi Aksara, 2004), 225

34 Indah Muliati and Muhamad Rezi, "Tujuan Pendidikan Dalam Lingkup Kajian Tafsir Tematik Pendidikan," ISLAM TRANSFORMATIF: Journal of Islamic Studies 1, no. 2 (2018): 177-90, doi:10.30983/IT.V1I2.475.

35 Alfurqan Alfurqan, Rini Rahman, and Muhamad Rezi, "Pendidikan Orang Dewasa Yang Dikembangkan "Rasulullah," ISLAM TRANSFORMATIF: Journal of Islamic Studies 1, no. 1 (August 7, 2017): 15-29, doi:10.30983/IT.V1I1.327.

Beliau dikenal sebagai pendidik yang memadukan antara konsep dan praktik. ${ }^{36}$

$\underline{\text { Guru }}$

Agar tujuan pendidikan tercapai dengan baik dan memuaskan, Mahmud Yunus memberi beberapa nasehat.

Guru harus mempunyai tekad dan kemauan yang kuat untuk menjadi pengajar dan pendidik bagi peserta didik.

Guru hendaknya memiliki ilmu pengetahuan yang luas dibandingkan peserta didiknya, agar guru mampu menata situasi kelasnya sebaik mungkin ketika proses pembelajaran, pun akan menumbuhkan kecintaan anak didik terhadap pelajaran tersebut. Guru juga tidak akan berhenti belajar, dan terus memperbaharui ilmu pengetahuannya.

Guru harus jujur dan ikhlas dalam melakukan pekerjaannya. Kejujuran dan keikhlasan merupakan cara terindah agar sukses dalam mengajar menuju sukses peserta didik dalam memahami pelajaran.

Guru harus mampu bergaul dengan guru lain serta pandai membawa diri dan saling menghormati.

Guru diharuskan berpakaian sopan, bersih, dan rapi.

Guru haruslah berbadan tegap, memiliki panca indra yang sehat, dan fasih dalam berbicara.

Guru harus berakhlak mulia, tertib dan sopan, terkhusus ketika berada di hadapan peserta didiknya.

Guru tidak boleh lupa, bahwa ia berhadapan dengan peserta didik pada usia 7 , 8, 9, 10, 11 dan 12 tahun. Karenanya, ia perlu menyesuaikan cara fikirnya, perasaannya, khayalnya, agar bisa sejiwa dengan mereka, baru kemudian membawa mereka ke tingkatan yang lebih tinggi dengan cara bertahap.

36 Tokoh-tokoh Islam..., 90 
Guru diharuskan ramah dengan peserta didiknya. Guru juga tidak boleh membedakan perlakuan antara peserta didik yang satu dengan peserta didik lainnya. Guru harus mengasihi semua muridnya.

Guru diharuskan selalu datang tepat waktu. ${ }^{37}$ Hendaklah guru datang ke sekolah tepat pada waktu yang telah ditentukan dan jangan pernah terlambat, agar guru menjadi contoh bagi peserta didiknya dalam menjaga waktu dan menepati janji.

Menurut Mahmud Yunus antara guru dan peserta didik harus memiliki hubungan jiwa yang erat, penuh kasih sayang, perumpamaannya seperti hubungan antara orang tua dan anak. Guru hendaknya memandang anak didiknya seperti anaknya sendiri. Guru berkorban waktu, tenaga dan fikirannya untuk kebaikan dan kesuksesan anak didiknya. Mahmud Yunus menegaskan larangan menggunakan kekerasan dan kemarahan dalam mendidik, dan seorang guru tidak boleh sama sekali memandang hina dan mengasingkan anak didiknya. Mahmud Yunus juga menekankan pentingnya berbaur dan bergaul dengan anak didik penuh kasih sayang, sehingga anak didik pun menyayangi gurunya. Guru merupakan pengganti orang tua bagi anak didik di sekolah, sehingga gurupun hendaknya bertindak selayaknya orang tua. Dalam pandangan Mahmud Yunus jika hendak memperbaiki pendidikan dan pengajaran di Indonesia, maka caranya adalah dengan memperbaiki guru-gurunya, cara memperbaiki guru-guru adalah dengan mempersiapkan guru-guru itu di sekolahsekolah guru (Mu'alimin atau Fakultas Tarbiyah). ${ }^{38}$

37 Mahmud Yunus, Metodik Khusus Pendidikan Agama, (Jakarta: Hidakarya Agung, 1980), 66

38 Mahmud Yunus. Pokok-Pokok Pendidikan dan Pengajaran, 60

\section{KESIMPULAN}

Mahmud Yunus merupakan salah satu tokoh pembaruan pendidikan Islam di Indonesia. Sebagai seorang tokoh pembaruan beliau mengembangkan beberapa teori pedagogik. Teori Pedagogik yang dikembangkannya adalah :

Tujuan pendidikan menurut Mahmud Yunus adalah menyiapkan anak-anak didik agar diwaktu dewasa kelak mereka sanggup dan cakap melakukan pekerjaan dunia dan amalan akhirat sehingga tercipta kebahagiaan bersama dunia dan akhirat

Mahmud Yunus melaksanakan sistem pengajaranbalaqah dan klasikal di Madras School, yang dikembangkan oleh Mahmud Yunus adalah sistem klasikal, sistem ini digunakannya dengan pendekatan aktivitas.

Mahmud Yunus dalam mengajar menggunakan metode ceramah, tanya jawab (dialog), pemberian tugas, demonstrasi, kerja kelompok dan uswatun hasanah (keteladanan). Dalam pengajaran Bahasa Arab Mahmud Yunus menggunakan Thariqah al-Mubasyarah atau metode langsung (direct metode). Dalam mengajar beliau menggunakan berbagai pendekatan yakni pendekatan rasional, emosional, dan praktis.

Untuk kurikulum, Mahmud Yunus merupakan tokoh yang mempelopori kurikulum yang bersifat integrated, yaitu kurikulum yang memadukan ilmu agama dan ilmu umum di lembaga pendidikan Islam. Beliau juga salah satu tokoh yang pertama kali memasukkan pelajaran umum ke madrasah, membuat laboratorium fisika, dan salah satu pendiri PGAI. Beliau juga orang yang pertama kali berusaha memasukkan Pendidikan Agama dalam kurikulum Pendidikan Umum yang bernaung di bawah Departemen Pendidikan Nasional.

Terakhir yang berhubungan dengan guru, menurut Mahmud Yunus kalau hendak memperbaiki pendidikan dan pengajaran di Indonesia, maka tak ada jalan melainkan 
dengan memperbaiki guru-gurunya. Tak ada jalan untuk memperbaiki guru-guru melainkan dengan mempersiapkan guru-guru itu di sekolah-sekolah guru (Mu'alimin atau Fakultas Tarbiyah). 


\section{DAFTAR KEPUSTAKAAN}

Alfurqan, Alfurqan, Rini Rahman, and Muhamad Rezi. "Pendidikan Orang Dewasa Yang Dikembangkan Rasulullah." ISLAM TRANSFORMATIF : Journal of Islamic Studies 1, no. 1 (August 7, 2017): 15-29. doi:10.30983/IT.V1I1.327.

E. Nugroho. et.al, Ensiklopedi Nasional, vol. 17, Jakarta: PT. Cipta Adi Pustaka, 1991.

Ghazali, A. Syukur, Pembelajaran Keterampilan Berbahasa; Dengan Pendekatan Komunikatif-Interaktif, Bandung: Aditama, 2010.

Ghofur, Saiful Amin, Profil Para Mufassir al-Quran, Yogyakarta: Pustaka Insan Madani, 2008.

Hashim, Rosnani, Reclaiming the Conversation: Islamic Intellectual Tradition in the Malay Archipelago, The Other Press, 2010.

Hermawan, Acep, Metodologi Pembelajaran Babasa Arab, Bandung: PT Remaja Rosdakarya, 2001

Ibrahim, Sulaiman, Pendidikan dan Tafsir "Kiprah Mahmud Mahmud Yunus dalam Pembaruan Islam", Jakarta: LEKAS, 2011.

Muhammad, Herry, Tokoh-Tokoh Islam yang Berpengaruh Abad 20, Jakarta: Gema Insani, 2006.

Muliati, Indah, and Muhamad Rezi. "Tujuan Pendidikan Dalam Lingkup Kajian Tafsir Tematik Pendidikan.” ISLAM TRANSFORMATIF: Journal of Islamic Studies 1, no. 2 (2018): 177-90. doi:10.30983/IT.V1I2.475.

Nata, Abuddin, Tokob-Tokob Pembaruan Pendidikan Islam, Jakarta: Raja Grafindo Persada, 2005.

Rahman, Rini, Dinovia Fannil Kher, and Yati Aisha Rani. "Pendidikan Islam Bagi Remaja (Upaya Penguatan Karakter Dengan Pendekatan Agama." ISLAM TRANSFORMATIF : Journal of Islamic Studies 1, no. 2 (March 6, 2018): 95-104. doi:10.30983/IT.V1I2.473.

Ramayulis, Sejarah Pendidikan Islam; Perubahan Konsep Filsafat dan Metodologi dari Era Nabi SAW sampai Ulama Nusantara, Jakarta: Kalam Mulia, 2011.

Ramayulis \& Samsul Nizar, Ensiklopedi Tokoh Pendidikan Islam; Mengenal Tokoh Pendidikan di Dunia Islam dan Indonesia, Ciputat: Quantum Teaching, 2005.

Rina, Malta, Pemikiran dan Karya Prof. Dr. Mahmud Yunus Tentang Pendidikan Islam (1920-1982). http://pasca.unand.ac.id/id. diunduh pada 26 Mei 2016.

Yunus, Mahmud, Riwayat Hidup Prof. DR. Mahmud Mahmud Yunus, Jakarta: Hidakarya, 1982. , Sejarah Pendidikan Islam di Indonesia, Jakarta: Mutiara, 1995.

, Pokok-pokok Pendidikan dan Pengajaran, Jakarta: Hidakarya Agung, 1990. , Metodik Khusus Pendidikan Agama, Jakarta: Hidakarya Agung, 1980.

Zuhairini dkk, Sejarah Pendidikan Islam, Jakarta: PT Bumi Aksara, 2004. 